Review Article

\title{
Interplay between the Adaptive Immune System and Insulin Resistance in Weight Loss Induced by Bariatric Surgery
}

\author{
José Romeo Villarreal-Calderón ${ }^{(D)},{ }^{1}$ Ricardo X. Cuéllar, ${ }^{1}$ Martín R. Ramos-González, ${ }^{1}$ \\ Nestor Rubio-Infante $\left(\mathbb{1}^{1},{ }^{1}\right.$ Elena C. Castillo $\mathbb{D}^{1},{ }^{1}$ Leticia Elizondo-Montemayor $\left({ }^{1},{ }^{1,2}\right.$ \\ and Gerardo García-Rivas $\mathbb{D}^{1,3}$ \\ ${ }^{1}$ Tecnologico de Monterrey, Escuela de Medicina y Ciencias de la Salud, Ave. Morones Prieto 3000, Monterrey, NL 64710, Mexico \\ ${ }^{2}$ Tecnologico de Monterrey, Centro de Investigación en Nutrición Clínica y Obesidad, Ave. Morones Prieto 300, Monterrey, \\ NL 64710, Mexico \\ ${ }^{3}$ Tecnologico de Monterrey, Centro de Investigación Biomédica, Hospital Zambrano Hellion, TecSalud, \\ San Pedro Garza Garcia NL 66278, Mexico
}

Correspondence should be addressed to Leticia Elizondo-Montemayor; lelizond@itesm.mx and Gerardo García-Rivas; gdejesus@itesm.mx

Received 19 January 2019; Revised 5 November 2019; Accepted 25 November 2019; Published 6 December 2019

Guest Editor: Fiammetta Monacelli

Copyright (c) 2019 José Romeo Villarreal-Calderón et al. This is an open access article distributed under the Creative Commons Attribution License, which permits unrestricted use, distribution, and reproduction in any medium, provided the original work is properly cited.

\begin{abstract}
Low-grade chronic inflammation plays a pivotal role among other pathophysiological mechanisms involved in obesity. Innate and adaptive immune cells undergo systemic proinflammatory polarization that gives rise to an increased secretion of proinflammatory cytokines, which in turn leads to insulin resistance. Bariatric surgery is currently the most effective treatment for obesity, as it brings on significant weight loss, glucose metabolism improvement, and a decrease in systemic inflammation biomarkers. After bariatric surgery, several changes have been reported to occur in adaptive immunity, including reduction in CD4+ and CD8+ T cell counts, a decrease in the Th1/Th2 ratio, an increase in B regulatory cells, and reduction in proinflammatory cytokine secretion. Overall, there seems to be a major shift in several lymphocyte populations from a proinflammatory to an anti-inflammatory phenotype. Furthermore, increased antioxidant activity and reduced lipid and DNA oxidation products have been reported after bariatric surgery in circulating mononuclear cells. This paper highlights the shift in the adaptive immune system in response to weight loss and improved insulin sensitivity, as well as the interplay between immunological and metabolic adaptations as a result of bariatric surgery. Finally, based on data from research, we propose several mechanisms such as changes in adaptive immune cell phenotypes and their by-products, recruitment in adipose tissue, reduced oxidative stress, and modification in metabolic substrate availability as drivers to reduce low-grade chronic inflammation after bariatric surgery in severe obesity.
\end{abstract}

\section{Introduction}

Obesity is defined as an excess of body fat. Body mass index (BMI) has been the most widely used parameter to assess and classify the grade of obesity. The World Health Organization defines obesity as a $\mathrm{BMI} \geq 30 \mathrm{~kg} / \mathrm{m}^{2}[1]$. In recent decades, obesity prevalence has risen to alarming levels. Global prevalence has increased from $3.2 \%$ in men and $6.4 \%$ in women in 1975 to $10.8 \%$ and $14.9 \%$, respectively, in 2014 [2]. Obesity has been associated with metabolic disorders such as insulin resistance [3], dyslipidemia [4], and nonalcoholic fatty liver disease [5] and with endocrine conditions such as type 2 diabetes mellitus (T2DM) [6], polycystic ovarian syndrome [7], and vitamin D deficiency [8]. Despite a strong epidemiological association indicating an increased risk for obese subjects to suffer metabolic comorbidities, it should be noted that a proportion of the obese population has no manifest disorder (the so-called "metabolically healthy obese"), while also a relatively small but considerable proportion of normal-weight subjects may suffer from the metabolic conditions associated with obesity [9]. Obesity has also been related to autoimmune diseases such as rheumatoid arthritis [10], psoriasis [11], and 
systemic lupus erythematosus [12]. Furthermore, obesity increases mortality [13] and diminishes quality of life [14].

The treatment for obesity has proven to be a difficult challenge. Lifestyle changes including a change of diet and an increase in physical activity have been widely approved as the first-line options [15]. Several drugs, indicated as a complementary treatment to lifestyle changes, have proven to be effective in achieving a weight loss of $5 \%[16,17]$. However, weight regain is a common problem given that only about $50 \%$ of the subjects have been found to achieve a weight loss of at least $5 \%$ after 8 years of an intensive lifestyle intervention [18]. On the other hand, bariatric surgery has been regarded as the most effective long-term treatment for obesity [19]. According to the clinical guidelines from the American Society for Metabolic and Bariatric Surgery, surgical procedures for weight loss are indicated for patients with a $\mathrm{BMI} \geq 40 \mathrm{~kg} / \mathrm{m}^{2}$, a $\mathrm{BMI} \geq 35 \mathrm{~kg} / \mathrm{m}^{2}$ with at least one obesity-associated comorbidity, or a $\mathrm{BMI} \geq 30 \mathrm{~kg} / \mathrm{m}^{2}$ with either T2DM or metabolic syndrome [20].

Obesity is regarded as a low-grade inflammatory state characterized by an elevation of acute-phase reactants and proinflammatory cytokines. Inflammation is driven by the immune response, which is classified into innate and adaptive immunity. The innate response, mediated by neutrophils and macrophages that rapidly migrate to the inflamed tissues to try to eliminate the offensive agent, is nonspecific but fastacting. On the other hand, the adaptive response is directed against a specific insult, mediated by $\mathrm{T}$ and $\mathrm{B}$ lymphocytes, which recognize specific epitopes with high affinity by the $\mathrm{T}$ cell receptor (TCR) or by antibody production, respectively. Both responses usually interact with and reinforce each other. For instance, macrophages act as antigen-presenting cells (APC) for T cells, and in turn, T cells secrete proinflammatory cytokines such as interferon- $\gamma$, which further activates macrophages [21, 22]. Specifically, the proinflammatory milieu associated with obesity is driven in part by adipose tissue macrophages, which are a component of the innate immune system. However, increasing recent evidence indicates that adaptive immune cells, such as $\mathrm{T}$ and $\mathrm{B}$ lymphocytes, play a crucial role in the activation and maintenance of such inflammatory state $[23,24]$. The purpose of this review is to highlight the alterations in the adaptive immune system that follow bariatric surgery-induced weight loss and the potential underlying mechanisms associated with the inflammatory milieu and the insulin resistance status.

\section{Low-Grade Chronic Inflammatory State in Obesity Is Driven by Both Innate and Adaptive Immune Cells}

Obesity is associated with a low-grade chronic systemic inflammatory state characterized by elevation of acute-phase proteins such as C-reactive protein (CRP) produced by the liver [25] and IL-6, secreted by adipocytes and adipose tissue macrophages [26-28], as well as by an increase in TNF- $\alpha$ by adipose tissue [29]. Although early studies failed to find a significant increase in circulating TNF- $\alpha$ in patients with obesity [30], recent reports have observed higher serum TNF- $\alpha$ among obese subjects [31]. TNF- $\alpha$ has been shown to be mainly secreted by macrophages [32] that infiltrate adipose tissue creating crown-like structures (CLS) around necrotic adipocytes [33]. The role of adaptive immunity in obesity has been partly described. B lymphocytes have also been found within CLS in human adipose tissue, although their role is not completely understood [34]. In addition, adipose tissue from obese subjects has been found to contain an increased number of both CD4+ and CD8+ T lymphocytes, which also secrete proinflammatory cytokines such as TNF- $\alpha$ and IFN- $\gamma$ [35]. Furthermore, increased waist circumference has been associated with increased expression of the activation markers CD25 and CD69 in T lymphocytes from adipose tissue [36]. Immune cells in peripheral blood have also been found to be related to inflammatory markers. Th1 cells are well known to secrete IFN- $\gamma$, a proinflammatory cytokine, while Th2 cells secrete IL-4, an interleukin with an antiinflammatory role [23]. Peripheral blood mononuclear cells (PBMCs) have been shown to exhibit a proinflammatory secretory profile in obese subjects $[37,38]$. Also, higher levels of the activation factor CD25 in T lymphocytes and increased Th1/Th2 ratios, correlated with insulin resistance assessed by the HOMA index, have been reported in obese subjects compared with lean or healthy overweight controls [39]. Furthermore, BMI has been found to be positively correlated with CD4+ effector memory T lymphocytes and negatively correlated with anti-inflammatory T regulatory (Treg) lymphocytes in severely obese subjects undergoing bariatric surgery [40].

Other specific $\mathrm{T}$ lymphocyte populations, such as mucosal-associated invariant T (MAIT) cells, have also been associated with the secretion of proinflammatory mediators. MAIT cells are innate-like T lymphocytes found in peripheral blood, intestinal mucosa, and the liver. Circulating MAIT cell numbers have been found to be reduced in patients with obesity and in those with T2DM. However, secretion of IL-17 by MAIT cells was increased in obese compared with the lean subjects. In addition, secretion of IL-2, granzyme B, and TNF- $\alpha$ was increased in T2DM. Noteworthy, both MAIT and CD8+ cells were found to be more abundant in omental adipose tissue than in peripheral blood in obese patients. These findings suggest a recruitment of MAIT cells by adipose tissue in obese subjects [41]. The polarization toward proinflammatory subpopulations of lymphocytes is a systemic phenomenon that has been observed in several tissues, including the skeletal muscle, liver, and pancreas [42].

The role of innate immunity in the development of obesity-associated low-grade chronic inflammation has been well studied. Mounting evidence indicates that despite the lack of an identified specific antigen, the adaptive immune system also participates in the development of this inflammatory state and exhibits proinflammatory polarization.

\section{Inflammation Drives Insulin Resistance}

Although a causative relationship between inflammation and insulin resistance is generally not regarded as proven, multiple evidence from studies in animal models and clinical trials that suggest that chronic inflammation may be a mechanism involved in the development of insulin resistance has been 
shown [43]. Adipose tissue-secreted TNF- $\alpha$ has been shown to induce insulin resistance in animal models [29] through activation of Janus $\mathrm{N}$ kinases (JNK) and serine phosphorylation of insulin receptor substrate (IRS) [44]. Both TNF- $\alpha$ and IL-6 have been associated with incident T2DM in casecontrol studies [45]. Furthermore, anti-TNF- $\alpha$ treatment has been able to reduce insulin resistance in rheumatoid arthritis [46] and in psoriasis [47]. Kinases have been shown to play a role in insulin resistance. IKKe (I $\kappa \mathrm{B}$ kinase $\varepsilon)$ and TBK1 (TANK-binding kinase 1) are noncanonical $\mathrm{I} \kappa \mathrm{B}$ kinases that stimulate IFN- $\alpha$ and IFN- $\beta$. While these kinases have been shown to increase in response to a high-fat diet, their inactivation, either by genetic knockout or by pharmacological drugs, has been shown to prevent obesity and insulin resistance in murine models [48, 49]. Furthermore, a novel dual inhibitor of IKK $\varepsilon$ and TBK1, amlexanox, has been shown to improve glycemic control in T2DM in a subset of patients with increased baseline inflammatory status [50]. In addition, IFN- $\gamma$ has been shown to decrease insulin sensitivity in human adipose tissue by downregulation of PI3K (fosfatidilinositol-3-kinase), inhibiting the adipocyte secretion of the lipogenic enzymes, fatty acid synthase, and lipoprotein lipase, in response to insulin [35]. A more detailed description of the mechanisms by which inflammatory mediators lead to insulin resistance may be found in the revision by Chen et al. [51]. Besides inflammation, other mechanisms leading to insulin resistance in obesity include mitochondrial dysfunction, hyperinsulinemia through a negative feedback loop, lipotoxicity, endoplasmic reticulum stress, hypoxia, and oxidative stress [52]. Therefore, inflammation is a clinically relevant mechanism, among others, that contributes to insulin resistance associated with obesity and a potential source of pharmacological target for the treatment of insulin resistance and even T2DM in some patients.

\section{Insulin Might Induce Changes in an Immune Cell Phenotype}

Lymphocytes express both glucose transporter 1 (GLUT1) and GLUT3. Alterations in lymphocyte glucose uptake have been demonstrated in T2DM. Diet-treated subjects recently diagnosed with T2DM were shown to have increased peripheral lymphocyte glucose uptake at 15 minutes but have decreased uptake at 30 and 60 minutes compared with healthy controls. In contrast, insulin-treated patients with longer duration of disease were shown to have increased lymphocyte glucose uptake at all time points [53]. In lymphocytes from healthy subjects, in vitro treatment with insulin at $50 \mathrm{mIU} / \mathrm{ml}$ was shown to increase lymphocyte glucose uptake at 30 minutes, as well as GLUT3 and GLUT4 expression. These findings demonstrate that peripheral lymphocytes react to insulin stimulation and, therefore, could represent a model for the study of insulin resistance [54].

In addition, in an in vitro model, insulin has been described to be promoting anti-inflammatory Th2 differentiation in CD4+ lymphocytes, an effect likely mediated by ERK (extracellular-signal-regulated kinase) phosphorylation. Interestingly, while the insulin receptor was not shown to be detected in resting $\mathrm{T}$ cells, it was significantly upregulated upon activation in both CD4+ and CD8+ cells [55]. Furthermore, lymphocytes from obese subjects were not shown to increase pAKT (protein kinase B) intracellular levels or to decrease the Th1/Th2 ratio upon in vitro stimulation with supraphysiological concentrations of insulin, as the lymphocytes from lean controls did, indicating that lymphocytes from obese subjects have an impaired response to insulin [39].

These results indicate that lymphocytes respond to insulin stimulation, a fact not widely explored. Furthermore, in conditions characterized by insulin resistance, such as obesity and T2DM, lymphocytes have an impaired response to insulin. Finally, lymphocytes from obese subjects are resistant to insulin-mediated Th2 differentiation in vitro. Therefore, Th1 polarization seen in obesity may be partially caused by insulin resistance. Whether this is a relevant mechanism in vivo requires further study.

\section{Bariatric Surgery Induces Significant Weight Loss}

Lifestyle changes have been indicated as the first-line treatment option for people with obesity, but weight loss has proven to be rather small. In the Look AHEAD interventional study, a mean weight loss of $8.5 \%$ was achieved after one year of an intensive lifestyle intervention, but after an 8 -year follow-up, only $50.3 \%$ were able to maintain a $5 \%$ weight loss [18]. In another lifestyle change interventional study, a 5\% weight loss was shown to be sufficient in order to increase insulin sensitivity in the adipose tissue, liver, and skeletal muscle, but not to reduce systemic inflammation markers. A significant decrease in CRP was proven to decrease only after a progressive weight loss of more than $15 \%$, although no significant changes were seen for IL-6, MCP-1, or white blood cell count [56]. In contrast, bariatric surgery has proven to induce a consistent significant and persistent weight loss. A pooled meta-analysis which included 25 studies concluded that bariatric surgery was more effective than nonsurgical interventions in achieving weight loss after a follow-up of one, two, and three years. Bariatric surgery was proven to achieve a weight loss of at least $20 \mathrm{~kg}$ higher compared with nonsurgical interventions [19]. A worldwide study estimated that bariatric surgery overall induces a weight loss of $30.5 \%$ at one-year follow-up [57].

Roux-en-Y gastric bypass (RYGB), laparoscopic sleeve gastrectomy (LSG), laparoscopic adjustable gastric banding (LAGB), and biliopancreatic diversion with duodenal switch (BPD-DS) are the most common bariatric surgical procedures (Figure 1). LAGB and LSG are traditionally regarded as merely restrictive methods, since the main effect of the operation is a reduction in gastric capacity. RYGB and BDP-DS induce a reduction in gastric capacity along with a malabsorptive component, given that a partial bypass of the small bowel is generated. The malabsorptive component is far more significant in BPD-DS due to the increased extent of the bypassed small bowel. Beyond their restrictive and malabsorptive mechanisms, LSG, RYGB, and BPD-DS lead to alterations in endocrine mechanisms by modulation of the secretion of gastrointestinal factors, such as ghrelin and 

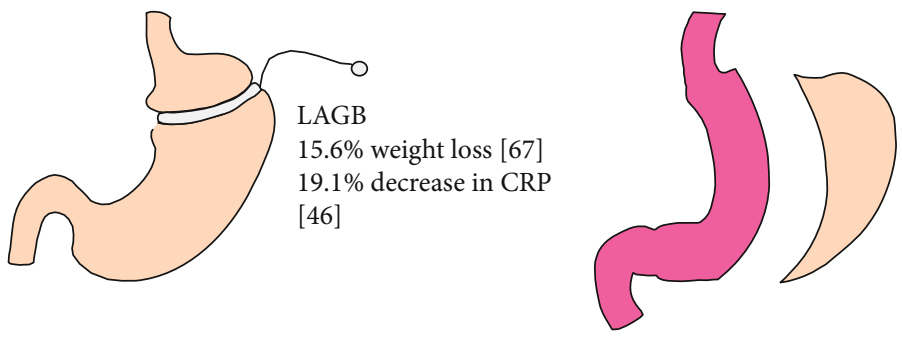

LSG

$33.4 \%$ weight loss [67]

$60.4 \%$ decrease in CRP

[78]
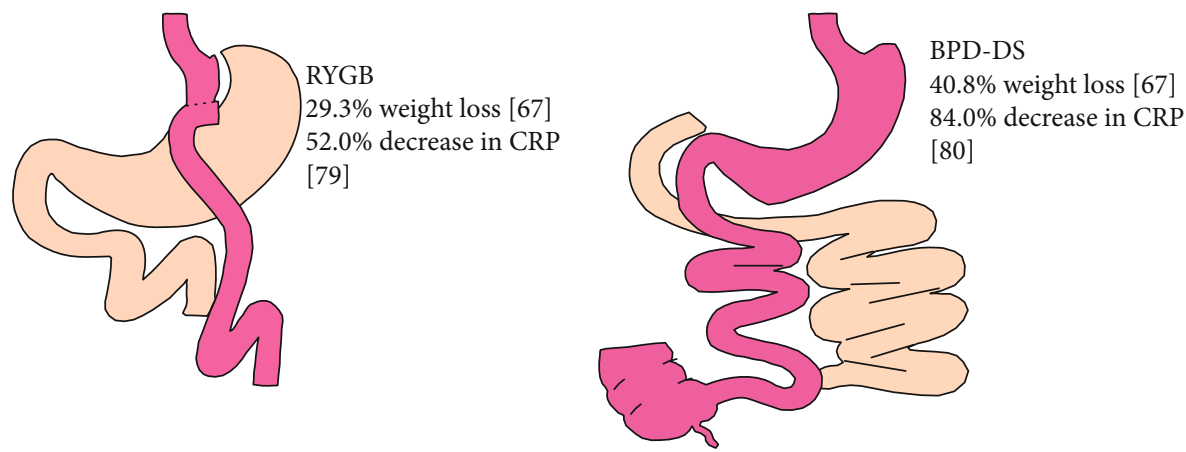

FIGURE 1: Graphic representation of bariatric surgical procedures to achieve weight loss and a \% decrease in CRP. LAGB: laparoscopic adjustable gastric band; LSG: laparoscopic sleeve gastrectomy; RYGB: Roux-en-Y gastric bypass; BPD-DS: biliopancreatic diversion with duodenal switch; CRP: C-reactive protein. References in brackets. Further details in text.

glucagon-like peptide 1 (GLP-1), which have an effect on satiety and on glucose metabolism $[58,59]$.

While RYGB is widely regarded as the "gold standard" of bariatric procedures, BPD-DS is considered more effective, since it induces greater weight loss. However, its increased technical complexity and the higher morbidity risk limit its use. Regarding weight loss with these different procedures, LSG weight loss outcomes are similar to those of RYGB, while LAGB induces a more modest weight loss $[58,59]$. In a retrospective study, a weight loss of $15.6 \%, 29.3 \%, 33.4 \%$, and $40.8 \%$ was achieved after a 3 -year follow-up using LAGB, RYGB, LSG, and BPD-DS, respectively [60] (Figure 1). Gastric imbrication or plicature, which involves folding and stitching the stomach into itself to adopt a tubular structure, is a relatively new surgical technique used for weight loss. Although there is little available data, short-term outcomes seem to be similar to those of sleeve gastrectomy [61]. In addition to weight loss, bariatric surgery is known to improve control of obesity-associated comorbidities, particularly T2DM and insulin resistance in the case of RYGB and BPD-DS, due to their endocrine component $[59,62]$.

\section{Bariatric Surgery Is Associated with a Decrease in Systemic Inflammation Assessed by C-reactive Protein}

Multiple studies have reported a decrease in CRP levels, a frequently assessed marker of systemic inflammation in the clinical setting after bariatric surgery. CRP has been shown to decrease from 1.15 to $0.34 \mathrm{mg} / \mathrm{l}$ at 6 months after either RYGB or LSG in a small cohort of Mexican subjects [63]. CRP was also found to fall from 0.68 to $0.55 \mathrm{mg} / \mathrm{dl} 3$ months after
LAGB, associated with a $13.9 \%$ weight loss, in 46 subjects [64]. In another study with a smaller sample size $(n=20)$, but a longer follow-up at 3 years, LAGB was shown to induce a weight loss of $30 \%$ and CRP was found to decrease from 7.6 to $3.4 \mathrm{mg} / \mathrm{l}$ [65]. CRP was found to be reduced from 5.3 to $2.1 \mathrm{U} / \mathrm{ml}$ one year after LSG in 30 morbidly obese women in which a $29.3 \%$ weight reduction was achieved [66]. Other authors have reported a decrease in CRP from 1.02 to $0.49 \mathrm{mg} / \mathrm{dl}$ in 20 obese subjects 3 months after RYGB. Noteworthy, no correlation was found between changes in CRP and changes in BMI. This lack of correlation points to a potential association of CRP with direct markers of fat mass or with caloric deprivation or malabsorption [67]. Finally, CRP was described to decrease from $11.9 \mathrm{~mol} / \mathrm{l}$ to $4.9 \mathrm{mmol} / \mathrm{l}$ at 6 months, with further reduction to $1.9 \mathrm{mmol} / \mathrm{l}$ at 12 -month follow-up in 70 subjects that underwent BPD-DS. Meanwhile, a $37.1 \%$ one-year weight loss was achieved [68]. Overall, all bariatric procedures were found to decrease CRP concentrations, although differences among the procedures might be attributable to the different follow-up periods and the varied baseline levels. It seems, however, that bariatric procedures that induce greater weight loss are also the most effective in reducing CRP levels and systemic inflammation (Table 1). However, other predictors of decreased CRP levels, such as adiposity markers or caloric deprivation, have been proposed.

\section{Weight Loss Induced by Bariatric Surgery Is Associated with a Systemic Decrease in Oxidative Stress Final Products}

Obesity has also been associated with high levels of oxidative stress in different studies. Obese women were found to have 
TABLE 1: Comparison of changes in systemic C-reactive protein observed after weight loss across different surgical procedures.

\begin{tabular}{|c|c|c|c|c|c|c|}
\hline Population & Mean age (years) & Intervention & Follow-up (months) & Weight loss (\%) & CRP reduction & Reference \\
\hline $\begin{array}{l}36 \text { subjects } \\
88.9 \% \mathrm{~F}\end{array}$ & 37 & RYGB/LSG & 6 & 24.3 & $70.4 \%$ & {$[63]$} \\
\hline $\begin{array}{l}46 \text { subjects } \\
87 \% \text { F }\end{array}$ & 40.6 & LAGB & 3 & 13.2 & $19.1 \%$ & {$[64]$} \\
\hline 20 subjects & & LAGB & 36 & 30.3 & $55.3 \%$ & {$[65]$} \\
\hline $\begin{array}{l}30 \text { subjects } \\
100 \% \mathrm{~F}\end{array}$ & 40.3 & LSG & 12 & $29.3 \%$ & $60.4 \%$ & {$[66]$} \\
\hline 70 subjects & 41.3 & BPD-DS & 12 & $37.1 \%$ & $84 \%$ & {$[68]$} \\
\hline
\end{tabular}

F: female; RYGB: Roux-en-Y gastric bypass; LSG: laparoscopic sleeve gastrectomy; LAGB: laparoscopic adjustable gastric band; BPD-DS: biliopancreatic diversion with duodenal switch; CRP: C-reactive protein.

higher plasmatic concentrations of lipid peroxidation and protein carbonylation markers, compared with normalweight controls. When measured 6 months after bariatric surgery, the levels of these markers were significantly reduced, although the concentrations did not reach those of the control group [69]. Short-term outcomes after biliopancreatic diversion have demonstrated an increase in glutathione-S-transferase and glutathione reductase activity in plasma, despite a decrease in glutathione peroxidase activity. Lipid peroxidation was found to increase initially 15 days after surgery, but afterwards, a significant decrease that remained below baseline levels 3 months after surgery was shown [70]. After a 1-year follow-up of bariatric surgery patients, a significant reduction in both lipid peroxidation and protein carbonylation, as well as an increase in nonprotein thiols and in whole blood antioxidant enzyme activity, was demonstrated [71]. Altogether, these results indicate an overall reduction in oxidative stress after weight loss induced by bariatric surgery.

Furthermore, bariatric surgery-mediated weight loss has been shown to reduce oxidative stress specifically in PBMCs, mainly composed of lymphocytes. Antioxidant enzyme activity has been reported to increase in PBMCs, while products of lipid and DNA oxidation have been shown to decrease after a one-year follow-up in morbid obese patients that underwent bariatric surgery $[72,73]$. Previous work indicates that mitochondrial ROS are necessary for $\mathrm{T}$ cell activation [74]. ROS modulation has been reported to reduce cytokine secretion $[75,76]$. Therefore, ROS reduction observed after bariatric surgery-induced weight loss should be expected to contribute to decreased proinflammatory cytokine secretion. However, its relevance in this specific clinical context has not been directly addressed.

\section{Bariatric Surgery Drives a Shift in Adaptive Immune Cells Characterized by Changes in Lymphocyte Count, Phenotype, and Anti-Inflammatory Marker Secretion}

Changes in lymphocyte count and variations in the phenotype, as well as in the secretion of their by-products, have been reported after bariatric surgery-induced weight loss. Shortly after gastric banding, a decrease in the Th1/Th2 ratio together with a reduction in Th1 and/or an increase in Th2 levels has been reported in T2DM and prediabetes, with improvement in glucose metabolism [77, 78]. B lymphocytes have also been shown to shift from an effector to a regulatory phenotype, suppressing proinflammatory cytokine secretion by $\mathrm{T}$ lymphocytes after RYGB [79]. In addition, the total number of CD4+ and CD8+ circulating $\mathrm{T}$ cells was found to be reduced after laparoscopic greater curvature plication in morbidly obese patients, suggesting a declined level of cell-mediated immune activity [80]. Likewise, a reduction in the count of B, T CD8+, and natural killer (NK) lymphocytes has been described after bariatric surgery in a subset of severely obese subjects with insulin resistance [81]. However, in a small sample of 20 severely obese women, no significant change in T CD4+, T CD8+, B, and NK lymphocyte subpopulations was found after bariatric surgery. When analyzed by the type of surgery, a change in CD4+ T lymphocytes was shown to correlate with changes in BMI in the RYGB subgroup, but not in the LAGB group, suggesting that more pronounced weight loss might be associated with a reduction in $\mathrm{CD} 4+\mathrm{T}$ cells [82]. Using another procedure, four months after laparoscopic greater curvature plication, a decrease in CD4+ T cells from $38.2 \%$ to $29.3 \%$, in CD8+ from $17.3 \%$ to $9.5 \%$, and in leptin from 43.01 to $24.8 \mathrm{ng} / \mathrm{ml}$ was demonstrated in 20 subjects [80]. However, the association between the observed changes in lymphocyte populations and leptin was not evaluated in the study. Considering these results, a weight loss-associated decrease in the inflammatory phenotype lymphocyte differentiation is induced after the diverse bariatric surgery procedures.

Furthermore, Tfh cells, which play a crucial role in activating and differentiating B lymphocytes, have been shown to reduce the expression of activation markers and the secretion of proinflammatory cytokines after RYGB. Activation markers of Tfh cells were found to be downregulated 3 months after RYGB. The secretion of IFN- $\gamma$, IL-2, IL-4, and IL-17 by Tfh cells was also shown to decrease, while no significant change was observed in IL-10. Secretion of IL-10 was described to be higher after $72 \mathrm{hr}$ incubation of Tfh post-RYGB plus staphylococcal enterotoxin B- (SEB-) pulsed autologous $B$ cells compared with that of Tfh pre-RYGB plus SEB-pulsed B cells. In addition, Tfh IL-10+ was shown to promote the differentiation of naïve $\mathrm{B}$ cells toward an IL-10- and TGF- $\beta$-secreting phenotype, directly mediated 
by IL-10 itself. B cells isolated after RYGB were found to express more IL-10 and TGF- $\beta$ [83]. These findings demonstrate an overall decrease in inflammatory cytokines and an overall increase in anti-inflammatory cytokines secreted by Tfh cells which may have a direct effect on the differentiation of anti-inflammatory B cells. Similarly, in another study, 3 months after the RYGB, B lymphocytes were found to shift from a proinflammatory IL-6+ phenotype to an anti-inflammatory IL-10+ phenotype, while T lymphocytes were shown to reduce the secretion of proinflammatory cytokines IL-17 and IFN- $\gamma$. Furthermore, coincubation of B and $\mathrm{T}$ cells showed that preoperative $\mathrm{B}$ cells stimulated proinflammatory cytokine secretion by $\mathrm{T}$ cells, while postoperative $B$ cells inhibited this phenomenon [79]. These findings indicate that bariatric surgery induces changes in the lymphocyte phenotype from proinflammatory to anti-inflammatory that further impact other cell populations to regulate their inflammatory potential.

Lips et al. [84] reported outcomes in inflammatory status in obese and diabetic women 3 months after RYGB. Weight loss was shown to lead to a reduction in systemic CRP, total $\mathrm{T}$ cells, and helper $\mathrm{T}$ cells, but paradoxically, also to an increase in TNF- $\alpha$ systemic concentration. It is speculated that this later finding may reflect incomplete recovery from the surgical procedure itself and that longer follow-up periods are recommended to get a better picture of systemic inflammation after bariatric surgery [84]. In addition, decreased circulating MAIT cell numbers with surprisingly increased proinflammatory IL-17 secretion have been found in obese subjects compared with healthy controls. The lower numbers of MAIT cells in obese subjects have been attributed to increased activation and infiltration in adipose tissue. After bariatric surgery, the subjects were reported to present increased MAIT cell count in peripheral blood, but with no decrease in IL-17 secretion [41]. The relevance of the changes in MAIT cells and whether they reflect a reduction in their proinflammatory phenotype require further study.

\section{Changes in Adaptive Cellular Immunity Elicited by Bariatric Surgery-Induced Weight Loss May Be Linked to Metabolic Improvement}

The relationship of lymphocyte changes induced by bariatric surgery-induced weight loss with insulin sensitivity and metabolic alterations is crucial. However, available data is scarce and somewhat controversial, though pointing toward a positive link between them. While some studies have found changes in cell immunity to be related to glucose metabolism, others have not shown such a relationship. Viardot et al. evaluated changes in the immune system induced by weight loss after a 24-week-long restriction diet with laparoscopic gastric banding (LGB) performed at week 12 in obese subjects with either T2DM or impaired glucose tolerance (IGT) and in 10 healthy matched control subjects. The mean weight loss was found to be $5 \%$ at week 12 and $13.5 \%$ at week 24 , while glucose control was described to improve significantly. Weight loss was shown to elicit a decrease in Th1 count and the Th1/Th2 ratio and to reduce the expression of CD69 and CD25 activation markers in lymphocytes. The decrease in CD69 and in the Th1/Th2 ratio was found to be associated with the reduction in BMI, but not with the HOMA-IR index or with fasting glucose [77]. However, other studies have shown a link between adaptive immune changes and metabolic parameters after bariatric surgery. The association between glucose metabolism and both systemic and adipose tissue inflammation was evaluated in 15 subjects with BMI above $35 \mathrm{~kg} / \mathrm{m}^{2}$ and either T2DM or IGT who underwent LGB. Weight loss of $12.5 \%$ at week 12 was found to lead to lower fasting glucose levels and to a decrease in the Th1/Th2 ratio. A negative correlation between Th2 levels and fasting glucose concentration was also found [78]. Likewise, in another study, a negative correlation between Tfh IL10+ cell percentage change and BMI, glucose levels, and fat mass percentage was found after RYGB [83]. As inflammation is one of the mechanisms leading to insulin resistance and other obesity-related comorbidities, an increase in the anti-inflammatory lymphocyte subpopulation associated with decreased glucose levels after bariatric surgery might suggest that changes in cellular immunity after weight loss are linked to metabolic improvements. Noteworthy, the absolute numbers of B lymphocytes, CD8+ T lymphocytes, and NK lymphocytes have been reported to decrease after BPD-DS only in insulin-resistant subjects, indicating a potential relationship between these lymphocyte populations and insulin resistance. It is possible that some of these lymphocytes, particularly NK cells, contribute to the development of insulin resistance [81]. On the other hand, another unexplored possibility is that insulin resistance might be the driver responsible for the changes in lymphocyte populations, which would reverse after bariatric surgery-related improvement in insulin sensitivity (Figure 2). Insulin has an effect on lymphocyte differentiation, but the role played by insulin in bariatric surgery-induced weight loss, as well as the potential effects on other lymphocyte populations besides that on CD4+ T cells, requires further study. Changes in lymphocyte populations and cytokine secretion seen after bariatric surgery-induced weight loss are summarized in Table 2.

\section{Shift to an Anti-Inflammatory Lymphocyte Phenotype after Bariatric Surgery and Weight Loss: From Insulin Resistance to Immunometabolism}

As previously described in this paper, bariatric surgery has been well known to considerably reduce white adipose tissue mass, to improve insulin resistance and T2DM, and to induce a shift from the proinflammatory condition that characterizes obesity to an anti-inflammatory state. However, the mechanism by which weight loss induces activation of immune system cells is not completely understood. We propose three main mechanisms based on reports that describe the relationship between postoperative weight loss and changes in the immune system.

The first mechanism involves the association of adipose tissue and chronic inflammation. The role of adipose tissue 


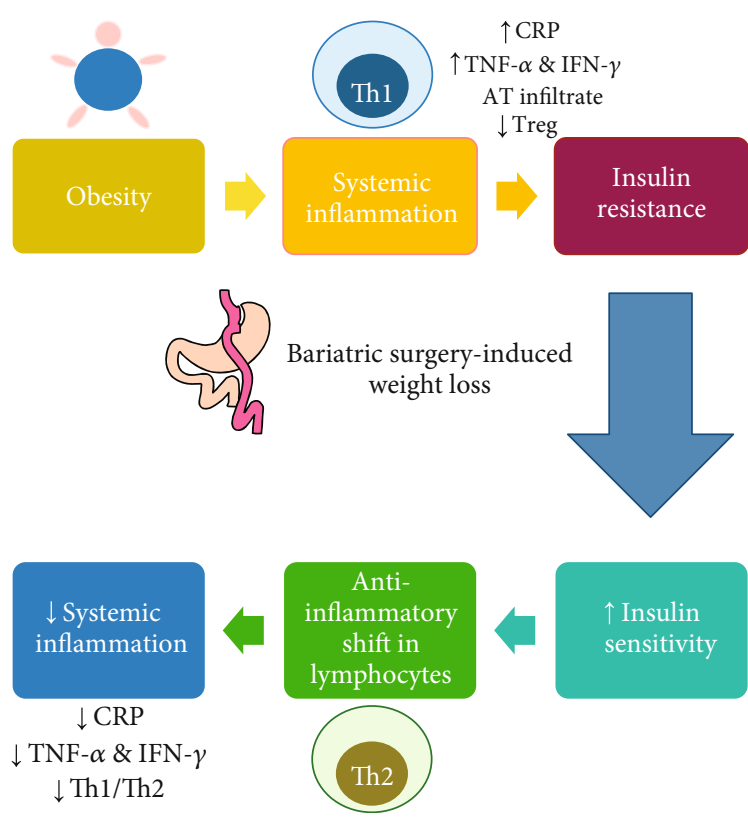

Figure 2: Potential mechanism of improvement in inflammatory status after bariatric surgery-induced weight loss. Obesity induces a systemic inflammatory status characterized by increases in C-reactive protein, proinflammatory cytokines such as TNF- $\alpha$ and IFN- $\gamma$, and an inflammatory infiltrate in adipose tissue (AT) and a decrease in circulating Treg lymphocytes. Inflammatory cytokines, among other mechanisms, induce insulin resistance in obesity. Bariatric surgery induces a significant weight loss that is associated with an increase in insulin sensitivity and a decrease in systemic inflammation. An important change in the lymphocyte phenotype is a decrease in the Th1/Th2 ratio after weight loss. It is possible that insulin effect on $\mathrm{T}$ cell differentiation may mediate inflammation resolution, at least partially.

in maintaining a low-grade chronic inflammation has been related to physiological stress in adipocytes as they progressively accumulate excessive fat. Increased release of inflammatory cytokines has been shown to elicit infiltration and activation of macrophages within the adipose tissue, which in turn alters the adipocyte secretion of adiponectin, leptin, and resistin. Thus, chronic insulin resistance is ensued and maintained [85]. Additionally, adipocyte death has been shown to induce immune cell activation and to initiate inflammation via macrophage activation [86]. The release of damage-associated molecular patterns (DAMPs) such as HMGB1 can lead to the activation of toll-like receptors (TLRs), and immune activation has also been described [87]. Also, differences in the localization of macrophages within adipose tissue between lean and obese fat mice have been found. In the lean group, interstitially spaced macrophages have been observed, while in the obese groups, macrophages are arranged in CLS [88], suggesting the presence of different subpopulations and paracrine activation. Therefore, the reduction of fat in the adipose tissue generated by bariatric surgery in the obese population would decrease the inflammatory stimulus driven by the interaction of immune cells and adipocytes.

The second mechanism involved in the relationship between postoperative weight loss and changes in the immune system is related to the activation and infiltration of immune cells. The reduction in the number and activation of infiltrating immune cells in the adipose tissue has been found to reduce the secretion of proinflammatory cytokines, such as CRP, IL-6, IL- $1 \beta$, TNF- $\alpha$, and IFN- $\gamma$, which in turn leads to a shift to an anti-inflammatory state and improves metabolic functions, contributing to weight loss. The interplay between the immune system and its associated effects on the metabolic status is a recent research field known as immunometabolism. Macrophages in lean adipose tissue have been described to have higher levels of arginase- 1 and IL-10 expression, which are typical markers of antiinflammatory M2 macrophages, compared with proinflammatory M1 macrophages found in obesity [89]. From this perspective, bariatric surgery could decrease infiltrating proinflammatory macrophages by reducing the differentiation of macrophages or by reestablishing the M1/M2 cell ratio, leading to a reduction in the infiltration of adaptive immune cells. Adaptive immunity in obesity has been shown to be affected by the infiltration of $\mathrm{T}$ and $\mathrm{B}$ cells into the adipose tissue, producing even more inflammatory cytokines, as demonstrated in obese mice $[42,90,91]$. After RYGB surgery, B cells have been shown to present a regulatory (IL-10) versus an effector (IL-6) profile and halt their previous role of sustaining $\mathrm{T}$ cell inflammation [79]. Bariatric surgery could modulate the increased activation of CD4+ and CD8+ T cells regularly observed in obese conditions and abate the level of both systemic inflammation and adipose tissue inflammation. In consequence, bariatric surgery can decrease or regularize the secretion of proinflammatory cytokines and insulin resistance, which in turn favors and improves glucose metabolism and adipogenesis (Figure 3 ).

The third mechanism involves the relationship of nutrients and immune cells. Metabolites such as glucose, free fatty acids, glutamine, and succinate are energy resources that can alter macrophage, neutrophil, and T cell functions [92]. Obesity is characterized by a continuous supply of these metabolites. The variations in these nutrient supplies observed after bariatric surgery could modulate the immune system and have been proposed as a key factor in immune differentiation. Bariatric surgery could modulate inflammation directly by decreasing the supply of nutrient metabolites through the inhibition of pathologic immune activation, hence leading to an anti-inflammatory state and improving metabolic functions. In particular, succinate has been shown to induce inflammation in macrophages via succinate receptor 1- (SUCNR1, also known as GPR91) mediated amplification of TLR signaling enhancing the secretion of IL-1 $\beta$ [93-94]. The metabolism of circulating fructose, which is mainly absorbed systemically by GLUT2 and GLUT5, has been associated with ATP depletion, oxidative stress, and inflammatory responses [95]. However, the cyclic guanosine-adenosine monophosphate (cGAMP) pathway has been described to be dysregulated, leading to the activation and induction of type I interferon synthesis induced by the STING receptor $[87,96]$. Obesity is associated with an increase in $\mathrm{T}$ effector memory cells and a decrease in naïve $\mathrm{T}$ cells. This polarization in T CD4+ cells is driven by palmitate and is mediated by the PI3K-Akt pathway. The protein mTORc2 
TABLE 2: Summary of changes in lymphocyte populations and cytokine secretion observed after bariatric surgery-induced weight loss.

\begin{tabular}{lcc}
\hline Population & Intervention & Main findings \\
\hline 13 subjects & & \\
BMI $\geq 35$ & 12 weeks of DCR $(860-1434$ kcal/day $)$ & $\downarrow$ Th1/Th2 after DCR; changes maintained \\
T2D or IGT & followed by LGB & 12 weeks after LGB \\
Age: $35-65$ & &
\end{tabular}

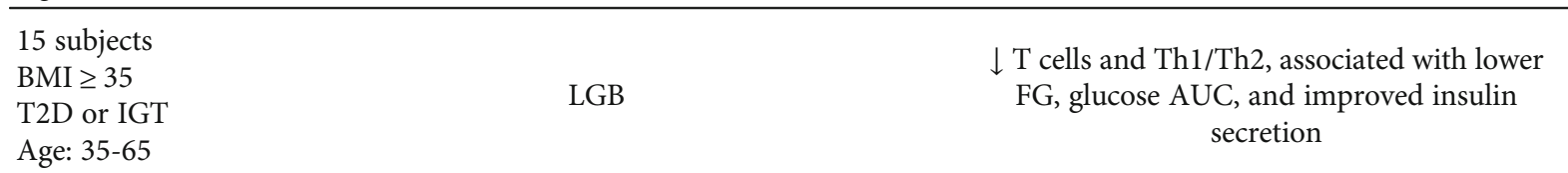

9 subjects

BMI: $35-38$

RYGB

3 months after: B cells lose the capacity to

support production of IL-17 and IFN- $\gamma$ by

$\mathrm{T}$ cells

\begin{tabular}{|c|c|c|}
\hline $\begin{array}{l}20 \text { subjects } \\
\text { BMI: } 37-45 \\
\text { Age: } 25-50\end{array}$ & Laparoscopic greater curvature plication & $\begin{array}{c}4 \text { months after: } \\
\qquad \text { CD4+ and CD8+ T cells } \\
\text { and leptin }\end{array}$ \\
\hline $\begin{array}{l}8 \text { subjects } \\
\text { BMI } \geq 40 \\
\text { With T2DM } \\
\text { Mean age: } 41.3\end{array}$ & RYGB & $\begin{array}{l}3 \text { months after: Tfh cells secreted: } \downarrow \text { IFN- } \gamma \text {, } \\
\text { IL- } 2 \text {, IL- } 4 \text {, and IL- } 17 \text { and } \uparrow \text { IL- } 10 \text {. Tfh IL- } 10+ \\
\text { promoted Breg cell differentiation and } \\
\text { predicted better clinical response }\end{array}$ \\
\hline
\end{tabular}

Age: 45-61 predicted better clinical response

\begin{tabular}{|c|c|c|}
\hline $\begin{array}{l}69 \text { subjects } \\
\mathrm{BMI} \geq 35\end{array}$ & & \\
\hline $\begin{array}{l}25 \% \mathrm{~T} 2 \mathrm{DM} \\
30 \text { subjects }\end{array}$ & RYGB & $\begin{array}{l}\uparrow \text { MAIT cells (potentially explained by } \downarrow \\
\text { peripheral infiltration); IL-17 remains }\end{array}$ \\
\hline
\end{tabular}

T2DM

$67 \%$ obese

\begin{tabular}{lcc}
\hline $\begin{array}{l}27 \text { women } \\
55.5 \% \text { obese }\end{array}$ & RYGB & $\begin{array}{c}3 \text { months after: } \downarrow \text { IR, CRP, leptin, and T cells; } \\
\uparrow \text { TNF- } \alpha\end{array}$ \\
\hline $\begin{array}{l}58 \text { subjects } \\
\text { Nondiabetic } \\
\text { BMI } \geq 40\end{array}$ & $\begin{array}{c}1 \text { year after BPD: } \downarrow \text { T cells and B cells in IR } \\
\text { subjects }\end{array}$ \\
$\begin{array}{l}6.8 \% \text { IR } \\
\text { Age: } 18-60\end{array}$ & 6 weeks of VLCD followed by BPD & $\begin{array}{c}\text { Correlation: changes in CD }+ \text { and HOMA } \\
\text { index }\end{array}$ \\
\hline
\end{tabular}

BMI: 36.4-68.2 LGB and RYGB

Age: $25-90$

LGB and RYGB
and CD4+ cells only in the RYGB group at 3 months

DCR: dietary caloric restriction; BMI: body mass index; T2DM: type 2 diabetes mellitus; IR: insulin resistance; LGB: laparoscopic gastric banding; RYGB: Roux-en-Y gastric bypass; VLCD: very low-calorie diet; BDP: biliopancreatic diversion; $\downarrow$ : decrease; $\uparrow:$ increase; FG: fasting glucose; MAIT: mucosal-associated invariant T cells; IR: insulin resistance; CRP: C-reactive protein; Ref: reference.

is involved in the activation of this pathway in an obese animal model [97].

Short-chain fatty acids (SCFAs), by-products of microbial fermentation, can drive the differentiation of $\mathrm{T}$ cell subsets. The potential for butyrate and propionate produced by commensal bacteria in the gut to promote Treg cell differentiation has been previously demonstrated [98-100]. Fatty acid oxidation (FAO) has been described to enhance the functions of M2-polarized macrophages. Also, glucose metabolism has been implicated in granulocyte, dendritic cell, and M1-type macrophage activation. Th1 and Th2 immune responses have been suggested to be supported by the oxidation of fatty acids, inducing the development of the CD8+ memory phenotype, M2-like macrophages, and Tregs [101, 102]. Particularly, a rapid supply of ATP has been found to increase bioenergetics requirements in CD8+
T cells, improving their activity. Conversely, abundant lactic acid and glucose deficiency have been shown to impair the function of these cells. Treg cells have been described to depend on oxidative phosphorylation for energy source, as they rely on FAO and glutaminolysis for cell differentiation and proliferation, respectively [103-105] Figure 4. As a result of the weight loss induced by bariatric surgery, the nutrient supply deprivation mechanism is regulated through decreased activation of most immune cells, resulting in a decreased systemic inflammatory state.

Gut microbiota represents a potential link between bariatric surgery and SCFAs. Changes in gut microbiota have been observed in overweight and obese patients. Variations in the bacterial composition of the microbiota and their distribution along the bowel have been associated with metabolic alterations such as insulin resistance, low-grade 

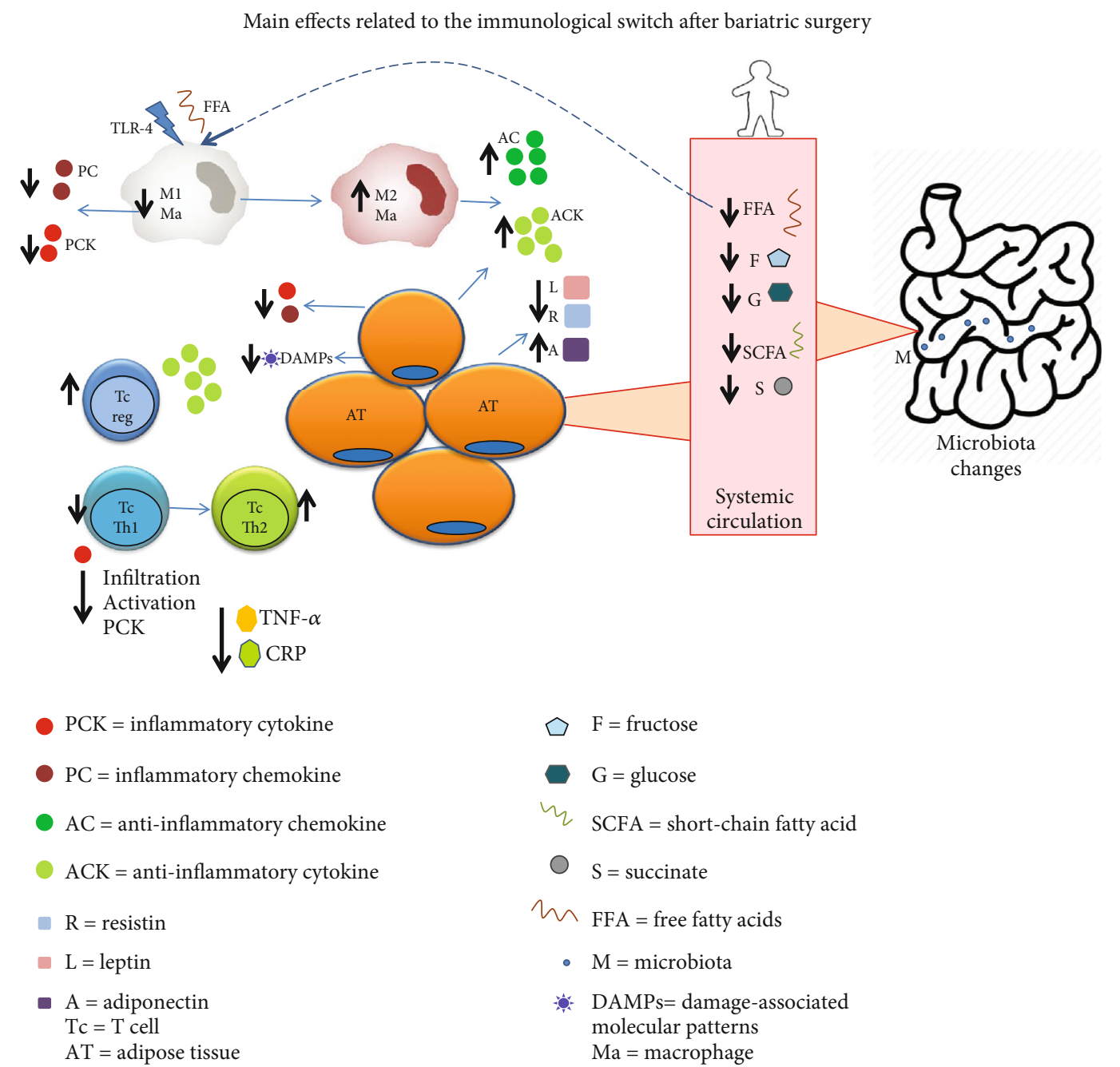

Figure 3: Main effects related to the immunological switch after bariatric surgery. Changes involved after weight loss include several molecular pathways: (i) a decrease in adipocyte proinflammatory mediators, (ii) changes in the activation and recruitment of immune cells in adipose tissue, (iii) modification in nutrient and metabolite absorption, and (iv) alterations in the intestinal microbiota.

Key role of metabolism in immune cell activation
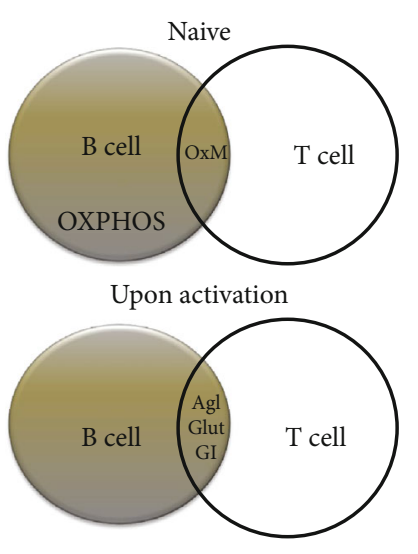

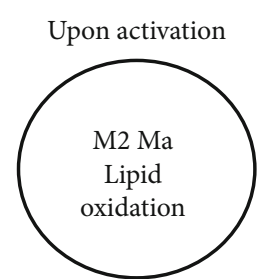

$\mathrm{OxM}=$ oxidative metabolism

$\mathrm{Agl}=$ anaerobic glycolysis

Glut $=$ glutaminolysis

$\mathrm{GI}=$ glucose intake

Figure 4: Metabolism modulates immune cell activation. Metabolic differences in naïve and activated T and B cells. Differences in energy supply between proinflammatory cells (M1 macrophages (M1 Ma)), dendritic cells (DC), granulocytes, and anti-inflammatory cells (M2 macrophages (M2 Ma)). 
inflammation, and adipocyte hypertrophy [106]. Reduced body weight and lower fat deposition have been found in a RYGB rat model compared with a sham group, attributed to a decrease in the absorption of SCFAs. SCFAs have been shown to be stored in the adipose tissue and to function as substrates for lipid and glucose metabolism, as well as immune cell modulators. As a consequence of fewer fatty acids being absorbed and stored in fat tissue, reduction in the secretion adipokines, growth factors, TNF- $\alpha$, IL-6, leptin, and resistin in fat tissue ensues [107], as well as improvement in the adaptive immune system cells with reduction of both local and systemic inflammations. Transfer of gut microbiota from RYGB-treated mice to nonoperated germ-free animals has been reported to lead to weight loss and changes in specific SCFAs compared with microbiota transfer from sham to surgery animals. Thus, changes in SCFA concentration caused by modification in gut microbiota after bariatric surgery may alter metabolic functions in the host [108]. Diet and obesity have been shown to induce dysbiosis in microbiota favoring immunogenic bacterial products $[109,110]$. Thus, immune system modulation after bariatric surgery might respond to changes in microbiota metabolic by-products.

\section{Conclusion}

Obesity is associated with a systemic low-grade inflammatory state in which cells from the innate and adaptive immune system increase proinflammatory cytokine secretion. Among other potential mechanisms, the inflammatory milieu leads to insulin resistance and metabolic comorbidities. An improvement in this deleterious condition is achieved through weight loss. Currently, bariatric surgery represents the most effective treatment option to induce significant and persistent weight loss. Weight loss induced by bariatric surgery leads to significant changes in adaptive immune cells. Both CD4+ and CD8+ T cell counts are reduced. Also, Tfh increases anti-inflammatory cytokine secretion, which leads to an increase in Breg cells. Anti-inflammatory cytokines, such as IL-10 and TGF- $\beta$ produced by Breg cells, inhibit the secretion of the proinflammatory cytokines IFN- $\gamma$ and IL-17 by T cells. Furthermore, a decrease in the Th1/Th2 ratio is also induced after bariatric surgery-mediated weight loss, probably related to improved insulin sensitivity. After bariatric surgery, immune cells develop stronger antioxidant capacity and reduce the level of lipid and DNA oxidation products. Oxidative stress is a known modulator of lymphocyte differentiation, metabolism, and proliferation, which improves after bariatric surgery. Changes in metabolic substrate availability after bariatric surgery, including glucose, succinate, and fatty acids, influence the adaptive immune response after bariatric surgery and still constitute a field that deserves further study. Palmitate, specifically, has been shown to promote $\mathrm{T}$ CD4+ effector memory cell differentiation in obesity. Mechanisms involved in bariatric surgeryinduced changes in adaptive immunity include weight loss per se, caloric deprivation, substrate availability, insulin sensitivity, fatty acid, and metabolite concentration changes. A better underpinning of the specific influence of each of these mechanisms on immune cell modulation in the context of bariatric surgery-mediated weight loss in the patient with severe obesity represents an open area of study. Further research focused on the interplay between the immune system pathways and the metabolic processes after bariatric surgery may lead to developments for the treatment of obesity and its associated comorbidities.

\section{Conflicts of Interest}

The authors declare that there is no conflict of interest regarding the publication of this paper.

\section{References}

[1] World Health Organization, "Obesity: preventing and managing the global epidemic: report of a WHO consultation," World Health Organization, Geneva, 2000.

[2] NCD Risk Factor Collaboration (NCD-RisC)," "Trends in adult body-mass index in 200 countries from 1975 to 2014: a pooled analysis of 1698 population-based measurement studies with 19.2 million participants," The Lancet, vol. 387, no. 10026, pp. 1377-1396, 2016.

[3] S. R. Preis, J. M. Massaro, S. J. Robins et al., “Abdominal subcutaneous and visceral adipose tissue and insulin resistance in the Framingham Heart Study," Obesity, vol. 18, no. 11, pp. 2191-2198, 2010.

[4] N. T. Nguyen, C. P. Magno, K. T. Lane, M. W. Hinojosa, and J. S. Lane, "Association of hypertension, diabetes, dyslipidemia, and metabolic syndrome with obesity: findings from the National Health and Nutrition Examination Survey, 1999 to 2004," Journal of the American College of Surgeons, vol. 207, no. 6, pp. 928-934, 2008.

[5] E. Fabbrini, S. Sullivan, and S. Klein, "Obesity and nonalcoholic fatty liver disease: biochemical, metabolic, and clinical implications," Hepatology, vol. 51, no. 2, pp. 679-689, 2010.

[6] M. L. Ganz, N. Wintfeld, Q. Li, V. Alas, J. Langer, and M. Hammer, "The association of body mass index with the risk of type 2 diabetes: a case-control study nested in an electronic health records system in the United States," Diabetology and Metabolic Syndrome, vol. 6, no. 1, p. 50, 2014.

[7] L. Elizondo-Montemayor, C. Hernández-Escobar, E. LaraTorre, B. Nieblas, and M. Gómez-Carmona, "Gynecologic and obstetric consequences of obesity in adolescent girls," Journal of Pediatric and Adolescent Gynecology, vol. 30, no. 2, pp. 156-168, 2017.

[8] L. Elizondo-Montemayor, E. C. Castillo, C. Rodríguez-López et al., "Seasonal variation in vitamin D in association with age, inflammatory cytokines, anthropometric parameters, and lifestyle factors in older adults," Mediators of Inflammation, vol. 2017, 14 pages, 2017.

[9] R. P. Wildman, P. Muntner, K. Reynolds et al., "The obese without cardiometabolic risk factor clustering and the normal weight with cardiometabolic risk factor clustering: prevalence and correlates of 2 phenotypes among the US population (NHANES 1999-2004)," Archives of Internal Medicine, vol. 168, no. 15, pp. 1617-1624, 2008.

[10] M. D. George and J. F. Baker, "The obesity epidemic and consequences for rheumatoid arthritis care," Current Rheumatology Reports, vol. 18, no. 1, p. 6, 2016. 
[11] A. R. Setty, G. Curhan, and H. K. Choi, "Obesity, waist circumference, weight change, and the risk of psoriasis in women: Nurses' Health Study II," Archives of Internal Medicine, vol. 167, no. 15, pp. 1670-1675, 2007.

[12] S. K. Tedeschi, M. Barbhaiya, S. Malspeis et al., "Obesity and the risk of systemic lupus erythematosus among women in the Nurses' Health Studies," Seminars in Arthritis and Rheumatism, vol. 47, no. 3, pp. 376-383, 2017.

[13] K. M. Flegal, B. K. Kit, H. Orpana, and B. I. Graubard, "Association of all-cause mortality with overweight and obesity using standard body mass index categories: a systematic review and meta-analysis," Journal of the American Medical Association, vol. 309, no. 1, pp. 71-82, 2013.

[14] R. Busutil, O. Espallardo, A. Torres, L. Martínez-Galdeano, N. Zozaya, and Â. Hidalgo-Vega, "The impact of obesity on health-related quality of life in Spain," Health and Quality of Life Outcomes, vol. 15, no. 1, 2017.

[15] T. A. Wadden, V. L. Webb, C. H. Moran, and B. A. Bailer, "Lifestyle modification for obesity: new developments in diet, physical activity, and behavior therapy," Circulation, vol. 125, no. 9, pp. 1157-1170, 2012.

[16] R. Khera, M. H. Murad, A. K. Chandar et al., "Association of pharmacological treatments for obesity with weight loss and adverse events: a systematic review and meta-analysis," Journal of the American Medical Association, vol. 315, no. 22, pp. 2424-2434, 2016.

[17] C. M. Apovian, L. J. Aronne, D. H. Bessesen et al., "Pharmacological management of obesity: an Endocrine Society clinical practice guideline," The Journal of Clinical Endocrinology and Metabolism, vol. 100, no. 2, pp. 342-362, 2015.

[18] The Look AHEAD Research Group, "Eight-year weight losses with an intensive lifestyle intervention: the look AHEAD study," Obesity, vol. 22, no. 1, pp. 5-13, 2014.

[19] J. Cheng, J. Gao, X. Shuai, G. Wang, and K. Tao, “The comprehensive summary of surgical versus non-surgical treatment for obesity: a systematic review and meta-analysis of randomized controlled trials," Oncotarget, vol. 7, no. 26, pp. 39216-39230, 2016.

[20] J. I. Mechanick, A. Youdim, D. B. Jones et al., "Clinical practice guidelines for the perioperative nutritional, metabolic, and nonsurgical support of the bariatric surgery patient2013 update: cosponsored by American Association of Clinical Endocrinologists, the Obesity Society, and American Society for Metabolic \& Bariatric Surgery," Surgery for Obesity and Related Diseases, vol. 9, no. 2, pp. 159-191, 2013.

[21] T. Zhou, Z. Hu, S. Yang, L. Sun, Z. Yu, and G. Wang, "Role of adaptive and innate immunity in type 2 diabetes mellitus," Journal Diabetes Research, vol. 2018, pp. 1-9, 2018.

[22] D. A. Cronkite and T. M. Strutt, "The regulation of inflammation by innate and adaptive lymphocytes," Journal of Immunology Research, vol. 2018, 14 pages, 2018.

[23] T. McLaughlin, S. E. Ackerman, L. Shen, and E. Engleman, "Role of innate and adaptive immunity in obesity-associated metabolic disease," The Journal of Clinical Investigation, vol. 127, no. 1, pp. 5-13, 2017.

[24] S. Winer and D. A. Winer, "The adaptive immune system as a fundamental regulator of adipose tissue inflammation and insulin resistance," Immunology and Cell Biology, vol. 90, no. 8, pp. 755-762, 2012.

[25] D. Aronson, P. Bartha, O. Zinder et al., "Obesity is the major determinant of elevated C-reactive protein in subjects with the metabolic syndrome," International Journal of Obesity, vol. 28, no. 5, pp. 674-679, 2004.

[26] A. L. Carey, C. R. Bruce, M. Sacchetti et al., "Interleukin-6 and tumor necrosis factor-? are not increased in patients with type 2 diabetes: evidence that plasma interleukin- 6 is related to fat mass and not insulin responsiveness," Diabetologia, vol. 47 , no. $6,2004$.

[27] M. Nikseresht, "Comparison of serum cytokine levels in men who are obese or men who are lean: effects of nonlinear periodized resistance training and obesity," Journal of Strength and Conditioning Research, vol. 32, no. 6, pp. 1787-1795, 2018.

[28] K. Eder, N. Baffy, A. Falus, and A. K. Fulop, "The major inflammatory mediator interleukin-6 and obesity," Inflammation Research, vol. 58, no. 11, pp. 727-736, 2009.

[29] G. S. Hotamisligil, N. S. Shargill, and B. M. Spiegelman, "Adipose expression of tumor necrosis factor-alpha: direct role in obesity-linked insulin resistance," Science, vol. 259, no. 5091, pp. 87-91, 1993.

[30] G. S. Hotamisligil, P. Arner, J. F. Caro, R. L. Atkinson, and B. M. Spiegelman, "Increased adipose tissue expression of tumor necrosis factor-alpha in human obesity and insulin resistance," The Journal of Clinical Investigation, vol. 95, no. 5, pp. 2409-2415, 1995.

[31] F. M. Schmidt, J. Weschenfelder, C. Sander et al., "Inflammatory cytokines in general and central obesity and modulating effects of physical activity," PLOS ONE, J. Eckel, Ed., vol. 10, no. 3, article e0121971, 2015.

[32] S. P. Weisberg, D. McCann, M. Desai, M. Rosenbaum, R. L. Leibel, and A. W. Ferrante, "Obesity is associated with macrophage accumulation in adipose tissue," The Journal of Clinical Investigation, vol. 112, no. 12, pp. 1796-1808, 2003.

[33] S. Cinti, G. Mitchell, G. Barbatelli et al., "Adipocyte death defines macrophage localization and function in adipose tissue of obese mice and humans," Journal of Lipid Research, vol. 46, no. 11, pp. 2347-2355, 2005.

[34] M. E. McDonnell, L. M. Ganley-Leal, A. Mehta et al., "B lymphocytes in human subcutaneous adipose crown-like structures," Obesity, vol. 20, no. 7, pp. 1372-1378, 2012.

[35] C. Duffaut, A. Zakaroff-Girard, V. Bourlier et al., "Interplay between human adipocytes and T lymphocytes in Obesity," Arteriosclerosis, Thrombosis, and Vascular Biology, vol. 29, no. 10, pp. 1608-1614, 2009.

[36] R. L. Travers, A. C. Motta, J. A. Betts, A. Bouloumié, and D. Thompson, "The impact of adiposity on adipose tissueresident lymphocyte activation in humans," International Journal of Obesity, vol. 39, no. 5, pp. 762-769, 2015.

[37] V. Catalán, J. Gómez-Ambrosi, A. Rodríguez et al., "Peripheral mononuclear blood cells contribute to the obesity-associated inflammatory state independently of glycemic status: involvement of the novel proinflammatory adipokines chemerin, chitinase-3-like protein 1, lipocalin-2 and osteopontin," Genes \& Nutrition, vol. 10, no. 3, p. 460, 2015.

[38] D. Dicker, M. A. Salook, D. Marcoviciu, M. Djaldetti, and H. Bessler, "Role of peripheral blood mononuclear cells in the predisposition of obese individuals to inflammation and infection," Obesity Facts, vol. 6, no. 2, pp. 146-151, 2013.

[39] A. Viardot, L. K. Heilbronn, D. Samocha-Bonet, F. Mackay, L. V. Campbell, and K. Samaras, "Obesity is associated with 
activated and insulin resistant immune cells," Diabetes/Metabolism Research and Reviews, vol. 28, no. 5, pp. 447-454, 2012.

[40] C. Agabiti-Rosei, V. Trapletti, S. Piantoni et al., "Decreased circulating $T$ regulatory lymphocytes in obese patients undergoing bariatric surgery," PLOS ONE, X. Cheng, Ed., vol. 13, no. 5, article e0197178, 2018.

[41] I. Magalhaes, K. Pingris, C. Poitou et al., "Mucosal-associated invariant $\mathrm{T}$ cell alterations in obese and type 2 diabetic patients," The Journal of Clinical Investigation, vol. 125, no. 4, pp. 1752-1762, 2015.

[42] Y. S. Lee, J. Wollam, and J. M. Olefsky, “An integrated view of immunometabolism," Cell, vol. 172, no. 1-2, pp. 22-40, 2018.

[43] M. Blüher, "Adipose tissue inflammation: a cause or consequence of obesity-related insulin resistance?," Clinical Science, vol. 130, no. 18, pp. 1603-1614, 2016.

[44] J. Hirosumi, G. Tuncman, L. Chang et al., "A central role for JNK in obesity and insulin resistance," Nature, vol. 420, no. 6913, pp. 333-336, 2002.

[45] J. Spranger, A. Kroke, M. Möhlig et al., "Inflammatory cytokines and the risk to develop type 2 diabetes: results of the prospective population-based European Prospective Investigation into Cancer and Nutrition (EPIC)-Potsdam Study," Diabetes, vol. 52, no. 3, pp. 812-817, 2003.

[46] A. N. Burska, R. Sakthiswary, and N. Sattar, "Effects of tumour necrosis factor antagonists on insulin sensitivity/resistance in rheumatoid arthritis: a systematic review and meta-analysis," PLOS ONE, M. Nurmohamed, Ed., vol. 10, no. 6, article e0128889, 2015.

[47] T. Pina, S. Armesto, R. Lopez-Mejias et al., “Anti-TNF- $\alpha$ therapy improves insulin sensitivity in non-diabetic patients with psoriasis: a 6-month prospective study," Journal of the European Academy of Dermatology and Venereology, vol. 29, no. 7, pp. 1325-1330, 2015.

[48] S.-H. Chiang, M. Bazuine, C. N. Lumeng et al., "The protein kinase IKKepsilon regulates energy balance in obese mice," Cell, vol. 138, no. 5, pp. 961-975, 2009.

[49] S. M. Reilly, S.-H. Chiang, S. J. Decker et al., "An inhibitor of the protein kinases TBK1 and IKK- $\varepsilon$ improves obesityrelated metabolic dysfunctions in mice," Nature Medicine, vol. 19, no. 3, pp. 313-321, 2013.

[50] E. A. Oral, S. M. Reilly, A. V. Gomez et al., "Inhibition of IKKe and TBK1 improves glucose control in a subset of patients with type 2 diabetes," Cell Metabolism, vol. 26, no. 1, pp. 157-170.e7, 2017.

[51] L. Chen, R. Chen, H. Wang, and F. Liang, "Mechanisms linking inflammation to insulin resistance," International Journal of Endocrinology, vol. 2015, Article ID 508409, 9 pages, 2015.

[52] J. Ye, "Mechanisms of insulin resistance in obesity," Frontiers in Medicine, vol. 7, no. 1, pp. 14-24, 2013.

[53] P. Piątkiewicz, A. Czech, and J. Taton, "Glucose transport in human peripheral blood lymphocytes influenced by type 2 diabetes mellitus," Archivum Immunologiae et Therapiae Experimentalis (Warsz), vol. 55, no. 2, pp. 119-126, 2007.

[54] P. Piatkiewicz, A. Czech, J. Tatoń, and A. Górski, "Investigations of cellular glucose transport and its regulation under the influence of insulin in human peripheral blood lymphocytes," Endokrynologia Polska, vol. 61, no. 2, pp. 182-187, 2010.

[55] A. Viardot, S. T. Grey, F. Mackay, and D. Chisholm, "Potential antiinflammatory role of insulin via the preferential polarization of effector $\mathrm{T}$ cells toward a $\mathrm{T}$ helper 2 phenotype," Endocrinology, vol. 148, no. 1, pp. 346-353, 2007.
[56] F. Magkos, G. Fraterrigo, J. Yoshino et al., "Effects of moderate and subsequent progressive weight loss on metabolic function and adipose tissue biology in humans with obesity," Cell Metabolism, vol. 23, no. 4, pp. 591-601, 2016.

[57] R. Welbourn, D. J. Pournaras, J. Dixon et al., "Bariatric surgery worldwide: baseline demographic description and one-year outcomes from the second IFSO Global Registry Report 2013-2015," Obesity Surgery, vol. 28, no. 2, pp. 313322, 2018 .

[58] J. L. Colquitt, K. Pickett, E. Loveman, and G. K. FramptonEndocrine Disorders Group, "Surgery for weight loss in adults," Cochrane Database of Systematic Reviews, C. Metabolic, Ed., no. 8, 2014.

[59] N. T. Nguyen and J. E. Varela, "Bariatric surgery for obesity and metabolic disorders: state of the art," Nature Reviews. Gastroenterology \& Hepatology, vol. 14, no. 3, pp. 160-169, 2017.

[60] M. Elrefai, T. Hasenberg, S. Diouf, C. Weiß, P. Kienle, and M. Otto, "Quality of life after bariatric surgery: comparison of four different surgical procedures," Bariatric Surgical Practice and Patient Care, vol. 12, no. 2, pp. 61-66, 2017.

[61] S. Sharma, M. Narwaria, D. R. Cottam, and S. Cottam, "Randomized double-blinded trial of laparoscopic gastric imbrication v laparoscopic sleeve gastrectomy at a single Indian institution," Obesity Surgery, vol. 25, no. 5, pp. 800-804, 2015.

[62] H. Buchwald, R. Estok, K. Fahrbach et al., "Weight and type 2 diabetes after bariatric surgery: systematic review and metaanalysis," The American Journal of Medicine, vol. 122, no. 3, pp. 248-256.e5, 2009.

[63] M. E. Rojano-Rodríguez, C. Valenzuela-Salazar, L. E. Cárdenas-Lailson, L. S. Romero Loera, M. Torres-Olalde, and M. Moreno-Portillo, "C-Reactive protein level in morbidly obese patients before and after bariatric surgery," Revista de Gastroenterología de México, vol. 79, no. 2, pp. 90-95, 2014.

[64] J. Santos, P. Salgado, C. Santos et al., "Effect of bariatric surgery on weight loss, inflammation, iron metabolism, and lipid profile," Scandinavian Journal of Surgery, vol. 103, no. 1, pp. 21-25, 2014.

[65] L. Iaffaldano, C. Nardelli, V. Pilone et al., "Laparoscopic adjustable gastric banding reduces subcutaneous adipose tissue and blood inflammation in nondiabetic morbidly obese individuals," Obesity Surgery, vol. 24, no. 12, pp. 2161-2168, 2014.

[66] G. Morshed and S. M. Fathy, "Impact of post-laparoscopic sleeve gastrectomy weight loss on C-reactive protein, lipid profile and CA-125 in morbidly obese women," Videosurgery and Other Miniinvasive Techniques, vol. 4, pp. 521-526, 2015.

[67] S. M. Zagorski, N. N. Papa, and M. H. Chung, "The effect of weight loss after gastric bypass on C-reactive protein levels," Surgery for Obesity and Related Diseases, vol. 1, no. 2, pp. 81-85, 2005.

[68] S.-M. Caron-Cantin, J. Martin, M. Bastien et al., "Acute and chronic effects of biliopancreatic diversion with duodenal switch surgery on plasma visfatin and apelin levels in patients with severe obesity," Obesity Surgery, vol. 23, no. 11, pp. 1806-1814, 2013.

[69] R. C. Horn, G. T. Gelatti, N. C. Mori et al., "Obesity, bariatric surgery and oxidative stress," Revista da Associação Médica Brasileira, vol. 63, no. 3, pp. 229-235, 2017. 
[70] M. Murri, E. García-Fuentes, J. M. García-Almeida et al., "Changes in oxidative stress and insulin resistance in morbidly obese patients after bariatric surgery," Obesity Surgery, vol. 20, no. 3, pp. 363-368, 2010.

[71] R. Schmatz, M. R. Bitencourt, L. D. Patias et al., "Evaluation of the biochemical, inflammatory and oxidative profile of obese patients given clinical treatment and bariatric surgery," Clinica Chimica Acta, vol. 465, pp. 72-79, 2017.

[72] L. Monzo-Beltran, A. Vazquez-Tarragón, C. Cerdà et al., "One-year follow-up of clinical, metabolic and oxidative stress profile of morbid obese patients after laparoscopic sleeve gastrectomy. 8-oxo-dG as a clinical marker," Redox Biology, vol. 12, pp. 389-402, 2017.

[73] E. E. Bankoglu, F. Seyfried, C. Arnold et al., "Reduction of DNA damage in peripheral lymphocytes of obese patients after bariatric surgery-mediated weight loss," Mutagenesis, vol. 33, no. 1, pp. 61-67, 2018.

[74] L. A. Sena, S. Li, A. Jairaman et al., "Mitochondria are required for antigen-specific $\mathrm{T}$ cell activation through reactive oxygen species signaling," Immunity, vol. 38, no. 2, pp. 225-236, 2013.

[75] E. Naik and V. M. Dixit, "Mitochondrial reactive oxygen species drive proinflammatory cytokine production," The Journal of Experimental Medicine, vol. 208, no. 3, pp. 417-420, 2011.

[76] M. Foster and S. Samman, "Zinc and regulation of inflammatory cytokines: implications for cardiometabolic disease," Nutrients, vol. 4, no. 7, pp. 676-694, 2012.

[77] A. Viardot, R. V. Lord, and K. Samaras, "The effects of weight loss and gastric banding on the innate and adaptive immune system in type 2 diabetes and prediabetes," The Journal of Clinical Endocrinology and Metabolism, vol. 95, no. 6, pp. 2845-2850, 2010.

[78] K. Samaras, A. Viardot, N. K. Botelho, A. Jenkins, and R. V. Lord, "Immune cell-mediated inflammation and the early improvements in glucose metabolism after gastric banding surgery," Diabetologia, vol. 56, no. 12, pp. 2564-2572, 2013.

[79] X. Dai, W. Zhao, J. Zhan et al., "B cells present skewed profile and lose the function of supporting $\mathrm{T}$ cell inflammation after Roux-en-Y gastric bypass," International Immunopharmacology, vol. 43, pp. 16-22, 2017.

[80] S. M. Fathy and G. Morshed, "Peripheral blood lymphocyte subsets (CD4+, CD8+ T cells), leptin level and weight loss after laparoscopic greater curvature plication in morbidly obese patients," Archives of Medical Science, vol. 5, no. 5, pp. 886-890, 2014.

[81] M. Ballesteros-Pomar, S. Calleja, R. Díez-Rodríguez et al., "Inflammatory status is different in relationship to insulin resistance in severely obese people and changes after bariatric surgery or diet-induced weight loss," Experimental and Clinical Endocrinology \& Diabetes, vol. 122, no. 10, pp. 592-596, 2014.

[82] Z. O. Merhi, H. G. Durkin, J. Feldman, J. Macura, C. Rodriguez, and H. Minkoff, "Effect of bariatric surgery on peripheral blood lymphocyte subsets in women," Surgery for Obesity and Related Diseases, vol. 5, no. 2, pp. 165-171, 2009.

[83] J. Zhan, L. Huang, H. Ma et al., "Reduced inflammatory responses of follicular helper $\mathrm{T}$ cell promote the development of regulatory B cells after Roux-en-Y gastric bypass," Clinical and Experimental Pharmacology \& Physiology, vol. 44, no. 5, pp. 556-565, 2017.
[84] M. A. Lips, J. B. van Klinken, H. Pijl et al., "Weight loss induced by very low calorie diet is associated with a more beneficial systemic inflammatory profile than by Roux-en-Y gastric bypass," Metabolism, vol. 65, no. 11, pp. 1614-1620, 2016.

[85] D. K. Hagman, I. Larson, J. N. Kuzma et al., "The short-term and long-term effects of bariatric/metabolic surgery on subcutaneous adipose tissue inflammation in humans," Metabolism, vol. 70, pp. 12-22, 2017.

[86] M. Kuroda and H. Sakaue, "Adipocyte death and chronic inflammation in obesity," The Journal of Medical Investigation, vol. 64, no. 3.4, pp. 193-196, 2017.

[87] Q. Chen, X. Guan, X. Zuo, J. Wang, and W. Yin, "The role of high mobility group box 1 (HMGB1) in the pathogenesis of kidney diseases," Acta Pharmaceutica Sinica B, vol. 6, no. 3, pp. 183-188, 2016.

[88] A. A. Hill, W. Reid Bolus, and A. H. Hasty, "A decade of progress in adipose tissue macrophage biology," Immunological Reviews, vol. 262, no. 1, pp. 134-152, 2014

[89] C. N. Lumeng, J. L. Bodzin, and A. R. Saltiel, “Obesity induces a phenotypic switch in adipose tissue macrophage polarization," The Journal of Clinical Investigation, vol. 117, no. 1, pp. 175-184, 2007.

[90] S. Winer, Y. Chan, G. Paltser et al., "Normalization of obesity-associated insulin resistance through immunotherapy," Nature Medicine, vol. 15, no. 8, pp. 921-929, 2009.

[91] D. Frasca, A. Diaz, M. Romero, T. Vazquez, and B. B. Blomberg, "Obesity induces pro-inflammatory B cells and impairs B cell function in old mice," Mechanisms of Ageing and Development, vol. 162, pp. 91-99, 2017.

[92] R. M. Loftus and D. K. Finlay, "Immunometabolism: cellular metabolism turns immune regulator," The Journal of Biological Chemistry, vol. 291, no. 1, pp. 1-10, 2016.

[93] A. Littlewood-Evans, S. Sarret, V. Apfel et al., "GPR91 senses extracellular succinate released from inflammatory macrophages and exacerbates rheumatoid arthritis," The Journal of Experimental Medicine, vol. 213, no. 9, pp. 1655-1662, 2016.

[94] Q. Zhang, Y. Lou, X.-L. Bai, and T.-B. Liang, "Immunometabolism: a novel perspective of liver cancer microenvironment and its influence on tumor progression," World Journal of Gastroenterology, vol. 24, no. 31, pp. 3500-3512, 2018.

[95] D.-M. Zhang, R.-Q. Jiao, and L.-D. Kong, "High dietary fructose: direct or indirect dangerous factors disturbing tissue and organ functions," Nutrients, vol. 9, no. 4, p. 335, 2017.

[96] F. Nicoli, S. Paul, and V. Appay, "Harnessing the induction of CD8+ T-cell responses through metabolic regulation by pathogen-recognition-receptor triggering in antigen presenting cells," Frontiers in Immunology, vol. 9, p. 9, 2018.

[97] C. Mauro, J. Smith, D. Cucchi et al., "Obesity-induced metabolic stress leads to biased effector memory CD4 + T cell differentiation via PI3K p110 $\delta$-Akt-mediated signals," Cell Metabolism, vol. 25, no. 3, pp. 593-609, 2017.

[98] N. Arpaia, C. Campbell, X. Fan et al., "Metabolites produced by commensal bacteria promote peripheral regulatory T-cell generation," Nature, vol. 504, no. 7480, pp. 451-455, 2013.

[99] Y. Furusawa, Y. Obata, S. Fukuda et al., "Commensal microbe-derived butyrate induces the differentiation of colonic regulatory T cells," Nature, vol. 504, no. 7480, pp. 446-450, 2013. 
[100] P. M. Smith, M. R. Howitt, N. Panikov et al., "The microbial metabolites, short-chain fatty acids, regulate colonic Treg cell homeostasis," Regulate Colonic Treg Cell Homeostasis. Science, vol. 341, no. 6145, pp. 569-573, 2013.

[101] L. A. J. O'Neill, R. J. Kishton, and J. Rathmell, “A guide to immunometabolism for immunologists," Nature Reviews. Immunology, vol. 16, no. 9, pp. 553-565, 2016.

[102] M. Agrawal, P. A. Kern, and B. S. Nikolajczyk, "The immune system in obesity: developing paradigms amidst inconvenient truths," Current Diabetes Reports, vol. 17, no. 10, p. 87, 2017.

[103] P. J. Siska and J. C. Rathmell, "T cell metabolic fitness in antitumor immunity," Trends in Immunology, vol. 36, no. 4, pp. 257-264, 2015.

[104] R. E. Wawman, H. Bartlett, and Y. H. Oo, "Regulatory T cell metabolism in the hepatic microenvironment," Frontiers in Immunology, vol. 8, p. 8, 2018.

[105] U. H. Beier, A. Angelin, T. Akimova et al., "Essential role of mitochondrial energy metabolism in Foxp $3^{+}$T-regulatory cell function and allograft survival," The FASEB Journal, vol. 29, no. 6, pp. 2315-2326, 2015.

[106] J. Aron-Wisnewsky, E. Prifti, E. Belda et al., "Major microbiota dysbiosis in severe obesity: fate after bariatric surgery," Gut, vol. 68, no. 1, pp. 70-82, 2019.

[107] P. Sinclair, D. J. Brennan, and C. W. le Roux, "Gut adaptation after metabolic surgery and its influences on the brain, liver and cancer," Nature Reviews. Gastroenterology \& Hepatology, vol. 15, no. 10, pp. 606-624, 2018.

[108] A. P. Liou, M. Paziuk, J.-M. Luevano, S. Machineni, P. J. Turnbaugh, and L. M. Kaplan, "Conserved shifts in the gut microbiota due to gastric bypass reduce host weight and adiposity," Science Translational Medicine, vol. 5, no. 178, p. 178ra41, 2013.

[109] Y. Sanz and A. Moya-Pérez, "Microbiota, inflammation and obesity," in Microbial Endocrinology: The Microbiota-GutBrain Axis in Health and Disease, M. Lyte and J. F. Cryan, Eds., pp. 291-317, Springer New York, New York, NY, 2014.

[110] A. Perez-Lopez, J. Behnsen, S.-P. Nuccio, and M. Raffatellu, "Mucosal immunity to pathogenic intestinal bacteria," Nature Reviews. Immunology, vol. 16, no. 3, pp. 135-148, 2016. 


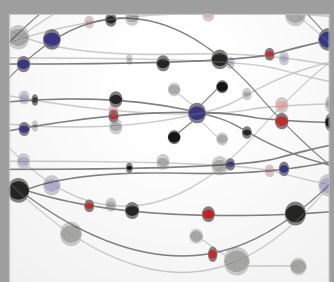

The Scientific World Journal
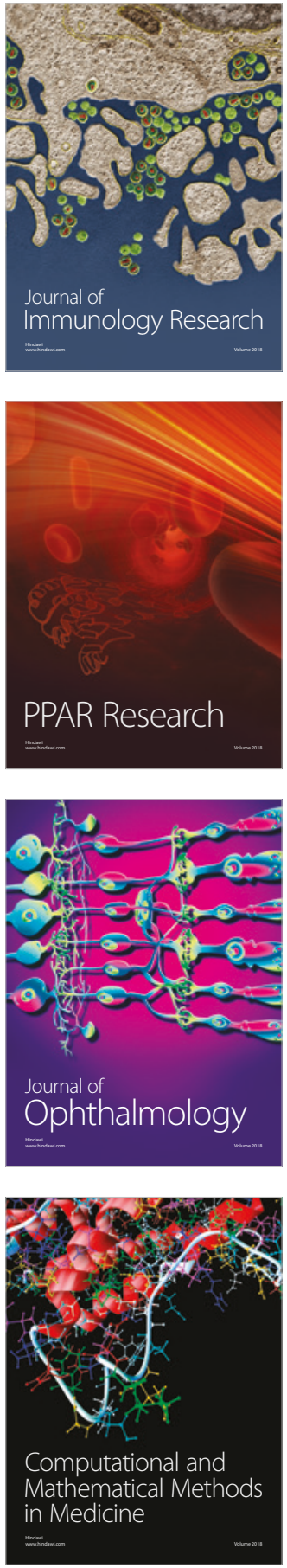

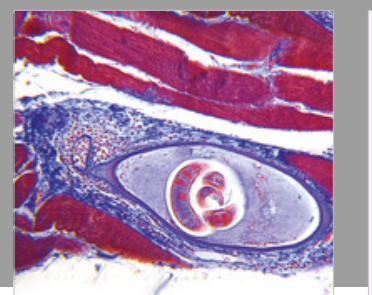

Gastroenterology Research and Practice

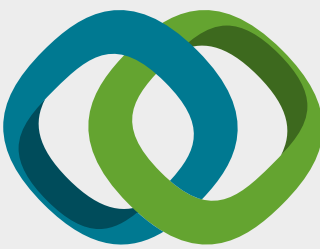

\section{Hindawi}

Submit your manuscripts at

www.hindawi.com
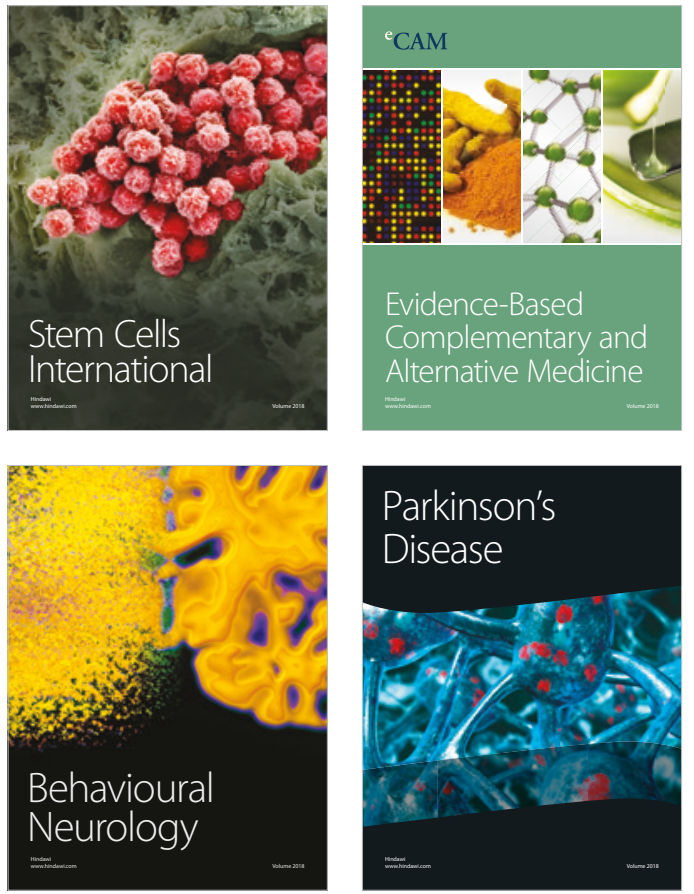

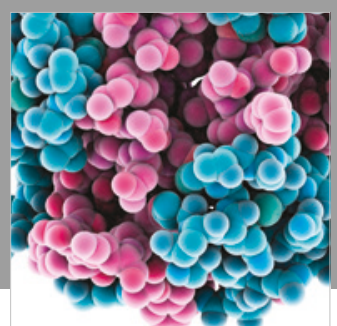

ournal of

Diabetes Research

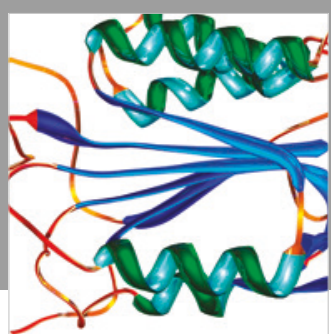

Disease Markers
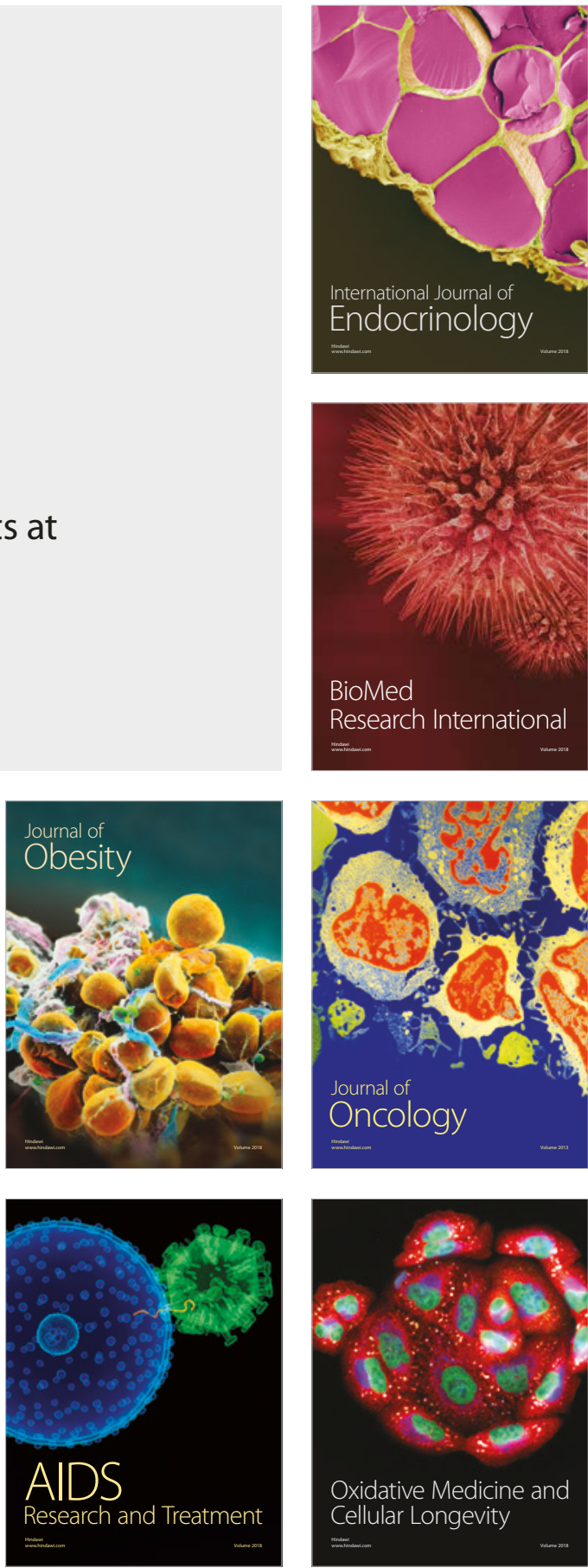